\title{
Development of Slag Minimum Refining Process by Desiliconization of Hot Metal ${ }^{*}$
}

\author{
By Yukiyoshi ITOH,** Shingo SATOH*** and Yuji KAWAUCHI***
}

\section{Synopsis}

New process "SMP" (Slag Minimum Refining Process) which consists of hot metal desiliconization stage in hot metal container and dephosphorization and decarburization stage in LD converter has been studied in order to reduce the consumption of refining fluxes and slag volume yield in conventional $L D$ process.

After experimental studies which have been carried out in $K R$ equipment and conventional $L D$ converter to estimate the feasibility of this new process, it becomes clear that hot metal desiliconization treatment can be done with simple equipment by using proper desiliconization agent and flux and its proper adding method.

By this new process, $\mathrm{CaO}$ consumption for dephosphorization in $L D$ converter and slag volume can be reduced drastically with decreasing $\mathrm{Si}$ content in hot metal and that $\mathrm{CaO}$ consumption and slag volume required is $18 \mathrm{~kg} / \mathrm{t}-\mathrm{s}, 42 \mathrm{~kg} / \mathrm{t}$-s at $\mathrm{Si}=0.15 \%$ for low carbon rimmed steel. As a result, lining life of refractory can be extended and the amount of metal and heat losses can be decreased and it makes the $L D$ refining very stable.

Based on the results obtained by the above experiments, a practical equipment of hot metal desiliconization treatment has been installed and came in use in October 1979, and now is in a stable operation.

\section{Introduction}

The LD process is presently the most common steelmaking process. It is characterized by the removal of carbon, silicon, manganese, phosphorus and sulphur in the same refining vessel. Further, this process is known for its excellent productivity. Therefore, in the age of high economic growth with the highest priority given to the securing of output, the principal role of the LD converter was to produce more crude steel from a given amount of hot metal than before by raising the scrap ratio using the carbon and silicon in hot metal as the source of heat. With changes in the situation of natural resources and energy after the oil crisis of 1973, however, it has become necessary to develop steelmaking techniques for effectively producing limited amount of crude steel.

With this background behind, the authors re-examined the conventional LD steelmaking process and commenced work on the development of an effective steelmaking process suited to the situation of change of natural resources and energy. As a result, they concluded that in order to increase the refining efficiency in the steelmaking process, it is of importance to limit the slag volume to within a certain range and, at the same time, to refine hot metal with having the slag volume kept constant. In other words, in order to reduce the slag volume, it is vital to save submaterials (especially $\mathrm{CaO}$ ). Furthermore, with a de- crease in the slag volume, a decrease in the amount of iron loss to slag, reduction of the erosion of refractories and other effects can be expected.

Based on the above-mentioned concept, the authors paid attention to the fact that reducing silicon content of hot metal to a certain level, is effective for reducing the slag volume. They conceived a new process, the slag minimum refining process (hereinafter called "SMP") based on the desiliconization treatment of hot metal, and conducted experiments to develop the SMP. As a consequence of this, the metallurgical advantage of the desiliconization of hot metal in the steel making process was ascertained and this new steelmaking process was successfully commercialized.

\section{Basic Concept of SMP}

As mentioned above, the silicon in hot metal was an important source of heat for increasing the scrap ratio in the days of high economic growth. Further, in the conventional $\mathrm{LD}$ steelmaking process, $\mathrm{SiO}_{2}$, an oxidation product of silicon, had the functions of lowering the melting point of formed slag for dephosphorization and increasing the slag formation ratio of $\mathrm{CaO}$. In addition, a certain amount of slag (100 to $120 \mathrm{~kg} / \mathrm{t}$-s) was considered necessary for dephosphorization and $\mathrm{SiO}_{2}$ was regarded as a component necessary for this treatment. Therefore, 0.4 to $0.7 \% \mathrm{Si}$ in hot metal was considered necessary in the conventional $\mathrm{LD}$ steelmaking process.

At present, however, there is little necessity of increasing the scrap ratio as before. As for $\mathrm{CaO}$, this sub-material is supplied for dephosphorization. Stoichiometrically, however, the amount of $\mathrm{CaO}$ that contributes to the dephosphorizing reaction is small and most of $\mathrm{CaO}$ is fixed to $\mathrm{SiO}_{2}$ as $2 \mathrm{CaO} \cdot \mathrm{SiO}_{2}$. Therefore, this means that $\mathrm{CaO}$ is supplied for the desiliconizing reaction that does not essentially require $\mathrm{CaO}$. A method of reducing the slag volume is conceivable which consists of separating the desiliconizing reaction from the dephosphorizing reaction. In this connection, the authors have already obtained some knowledge of the metallurgical advantage of the desiliconization of hot metal. The dephosphorization process of hot metal involves a preliminary desiliconization-dephosphorization method (two-step dephosphorization process ${ }^{1,2)}$ developed by the authors for the production of stainless steel by the LD process.

\footnotetext{
* Originally published in Tetsu-to-Hagané, 67 (1981), 2675, in Japanese; Formerly presented to the 98th ISIJ Meeting, October 1979, at Nagoya University in Nagoya. English version received July 19, 1982. (C) 1983 ISIJ

** Process Technology R \& D Laboratories, Nippon Steel Corporation, Edamitsu, Yawatahigashi-ku, Kitakyushu 805.

*** Muroran Works, Nippon Steel Corporation, Nakamachi, Muroran 050.
} 
In this process, prior removal of silicon enabled dephosphorization to occur with only 30 to $40 \mathrm{~kg}$ of slag per tonne of steel in spite of high carbon contents of about $3 \%$.

A conception of the SMP based on the desiliconization treatment of hot metal was formed from these findings. The basic concept of the new process is summarized as follows:

(1) For dephosphorization, it is necessary to secure only the $\mathrm{CaO}$ that participates in the reaction and it is unnecessary to use a large volume of slag as required in the conventional LD steelmaking process. Therefore, silicon that fixes most of $\mathrm{CaO}$ should be limited to within a certain range and slag formation by $\mathrm{CaO}$ at a low $\mathrm{Si}$ content is also possible by utilizing fluxes such as $\mathrm{CaF}_{2}$.

(2) It has become unnecessary to increase the scrap ratio. In addition, the loss of the sensible heat of slag decreases due to a decrease in the amount of slag formed. For these reasons, the heat of reaction generated mainly by carbon removal is sufficient as the source of heat.

In consideration of the efficiency and equipment in the steelmaking process, it is beneficial to utilize the existing LD converter as the dephosphorization and decarburization vessel in developing the new process. From this standpoint of view, the following two points were regarded as technical key points for the development of the SMP and experiments were carried out:

(1) Development of a simple technique of hot metal desiliconization that permits good matching with the existing LD converter operation.

(2) Establishment of a technique for dephosphorization in LD converter at a lower Si content of hot metal.

\section{Experiments for Development of the SMP}

\section{Experimental Method}

\section{Desiliconization of Hot Metal by Solid Iron Oxide}

The treatment in a hot metal transportation vessel was conceived as a simple desiliconization technique for hot metal. A small amount of flux was added during mechanical stirring using KR equipment (hot metal desulphurization equipment by the mechanical stirring method). Then, desiliconization treatment was carried out by feeding the desiliconization agents, mill scale and sinter, at a constant rate. Table 1 shows the experimental conditions.

From the consideration of exhaust gas and of the loss of manganese which is a valuable component, it is important in the desiliconization experiment to clarify conditions for retarding the oxidation of carbon and manganese and promoting only the desiliconizing reaction, i.e., preferential desiliconizing conditions.

Desiliconization treatment by the top blowing method using gaseous oxygen is also conceivable. However, this method requires oxygen blowing equipment. In addition, the scale of exhaust gas treatment equipment must be large because the decar- burization reaction proceeds at the same time. For these and other reasons, this method can not be said a simple desiliconization technique and, hence, was not taken into consideration.

\section{LD Refining of Low-silicon Hot Metal}

Low-silicon hot metal obtained through the desiliconization treatment was refined in $50 \mathrm{t}$ and $120 \mathrm{t}$ LD converters. Table 2 summarizes the experimental conditions. The oxygen blowing conditions are almost the same as those for the conventional LD steelmaking process. The amount of $\mathrm{CaO}$ added was reduced in proportion to the decrease in silicon content based on the basic concept of the SMP, and examination was made to find the volume of $\mathrm{CaO}$ and slag necessary for dephosphorization. Further, the metallurgical characteristics in this case were also investigated. As to the slag formed, examination was made to find a method of effectively utilizing both desiliconized slag and LD slag by making the most their features.

\section{Experimental Results}

1. Hot Metal Desiliconization by Solid Iron Oxide

(1) Behaviour of Components of Hot Metal

Figure 1 shows the desiliconization behavior during the treatment. As is apparent from the figure, silicon decrease almost linearly to $0.2 \%$ and after

Table 1. Experimental condition of desiliconization treatment of hot metal.

\begin{tabular}{|c|c|c|c|c|c|c|}
\hline $\begin{array}{l}\text { Hot } \\
\text { metal }\end{array}$ & \multicolumn{2}{|c|}{$\begin{array}{l}\text { Weight } \\
\text { Initial } \mathrm{Si} \\
\text { Initial temperature }\end{array}$} & \multicolumn{4}{|c|}{$\begin{array}{l}55 \sim 65 \mathrm{t} / \text { ladle } \\
0.40 \sim 0.72 \% \\
1330 \sim 1380^{\circ} \mathrm{C}\end{array}$} \\
\hline \multirow{5}{*}{ 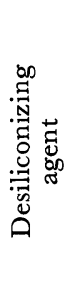 } & $\begin{array}{l}\text { Kind of ag } \\
V_{\mathrm{O}_{2}}{ }^{*}\end{array}$ & & & $\begin{array}{l}\text { ale or } \mathrm{S} \\
\sim 2.7 \mathrm{~N}\end{array}$ & $\begin{array}{l}\text { inter } \\
\mathrm{Jm}^{3} / \mathrm{mi}\end{array}$ & $\cdot t-p$ \\
\hline & \multicolumn{6}{|c|}{ Chemical composition (wt \%) } \\
\hline & & T.Fe & $\mathrm{FeO}$ & $\mathrm{Fe}_{2} \mathrm{O}_{3}$ & $\mathrm{SiO}_{2}$ & $\mathrm{CaO}$ \\
\hline & Scale & 70.5 & 59.3 & 34.8 & 1.7 & 一 \\
\hline & Sinter & 56.4 & 6.0 & 73.9 & 6.0 & 10.0 \\
\hline Flux & \multicolumn{6}{|c|}{$\mathrm{GaO}, \mathrm{Na}_{2} \mathrm{CO}_{3}, \mathrm{CaF}_{2}, \mathrm{~B}_{2} \mathrm{O}_{3} * *$} \\
\hline
\end{tabular}

$*$ Velocity of oxygen supply; $* *$ Colemanite : $2 \mathrm{CaO}, 3 \mathrm{~B}_{2} \mathrm{O}_{3}$

Table 2. Experimental condition of LD refining.

\begin{tabular}{|c|c|c|c|}
\hline & & $50 \mathrm{t} \mathrm{LD}$ & $120 \mathrm{t} \mathrm{LD}$ \\
\hline \multirow{2}{*}{$\begin{array}{l}\text { Blow } \\
\text { pattern }\end{array}$} & $\begin{array}{l}\mathrm{O}_{2} \text { blow } \\
\left(\mathrm{Nm}^{3} / \mathrm{h}\right)\end{array}$ & $8000 \sim 10000$ & $17000 \sim 18000$ \\
\hline & $\begin{array}{l}\text { Lance height } \\
(\mathrm{mm})\end{array}$ & $1300 \sim 1500$ & $1200 \sim 1400$ \\
\hline \multirow{4}{*}{$\underset{(\mathrm{kg} / \mathrm{t}-\mathrm{p})}{\text { Flux }}$} & $\mathrm{CaO}$ & $15 \sim 30$ & $15 \sim 30$ \\
\hline & $\mathrm{Fe}_{2} \mathrm{O}_{3}$ & $0 \sim 53$ & $0 \sim 40$ \\
\hline & $\mathrm{CaF}_{2}$ & $0 \sim 5$ & $0 \sim 3$ \\
\hline & Dolomite & $0 \sim 10$ & $0 \sim 15$ \\
\hline \multirow{2}{*}{$\begin{array}{l}\text { Hot } \\
\text { metal }\end{array}$} & {$[\% \mathrm{Si}]$} & $0.15 \sim 0.32$ & $0.10 \sim 0.35$ \\
\hline & $\mathrm{H} \cdot \mathrm{M} \cdot \mathrm{R}(\%)$ & $85 \sim 100$ & $83 \sim 100$ \\
\hline \multicolumn{2}{|c|}{ Final $[\% \mathrm{C}]$} & $0.06 \sim 0.60$ & $0.05 \sim 0.15$ \\
\hline
\end{tabular}


that, it tends to decrease exponentially. Figure 2 shows the relationship between the quantity of desiliconizing agents and the amounts of desiliconization. The amount of desiliconization increase in proportion to the quantity of desiliconizing agent. Mill scale is supplied in quantities of 7 to $8 \mathrm{~kg} / \mathrm{t}-\mathrm{p}$ and the amount of desiliconization is about $0.10 \%$ in this case. Mill scale showed better results than sinter even when it was supplied in smaller quantities.

As shown in Fig. 3, the amount of demanganization increase with decreasing silicon after treatment, but the lower the apparent velocity of oxygen supply, $V_{\mathrm{O}_{2}}$, based on the gaseous oxygen conversion, which will be described later, the more demanganization is retarded. The amount of decarburization is, as shown in Fig. 4, mostly $0.20 \%$ or less and is as small as $0.10 \%$ at $V_{\mathrm{O}_{2}}<1.0 \mathrm{Nm}^{3} / \mathrm{min}$ t-p. The fact that decarburization little proceeds is one of the features of the desiliconization treatment by solid iron oxide. (2) Slag Formed

The slag formed after the desiliconization treatment is, as shown in Table 3, an $\mathrm{SiO}_{2}-\mathrm{MnO}-\mathrm{FeO}$ slag,

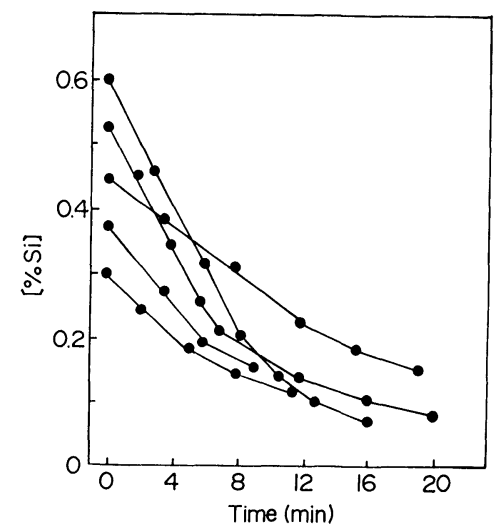

Fig. 1. Desiliconization behavior by desiliconization treatment.
$\mathrm{SiO}_{2}$ being the main component. It was expected that this slag would form strong silicate networks, thus making slag-cutting difficult. Therefore, an improvement in the slag-cutting property of various fluxes was investigated and colemanite $\left(2 \mathrm{CaO} \cdot 3 \mathrm{~B}_{2} \mathrm{O}_{3}\right)$ was found most effective even when used in a small quantity. The effect of colemanite is considered mainly due to the formation of low-viscosity slag resulting from the lower melting point of desiliconized slag.

(3) Iron and Heat Losses and Volume of Slag Formed

There is a tendency that both the temperature drop as the heat loss during the desiliconization treatment and the $\mathrm{T} . \mathrm{Fe}(\%)$ in slag as iron loss proceed in proportion to the quantity of desiliconizing agent. Therefore, to control iron and heat losses, it is necessary to promote preferential desiliconization as far as possible.

The volume of slag formed by the desiliconization treatment was measured. As shown in Fig. 5, the volume of slag formed increases in proportion to the

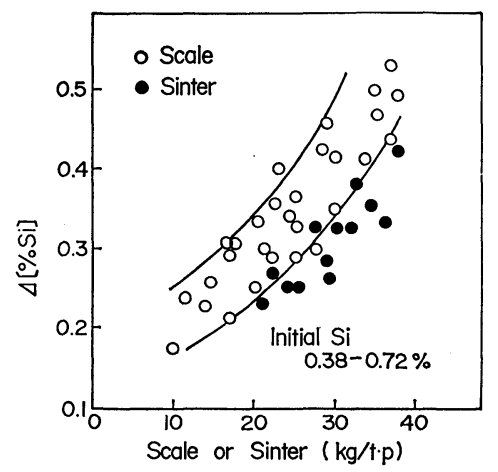

Fig. 2. Relation between quantity of desiliconizing agent and $\Delta[\% \mathrm{Si}]$.

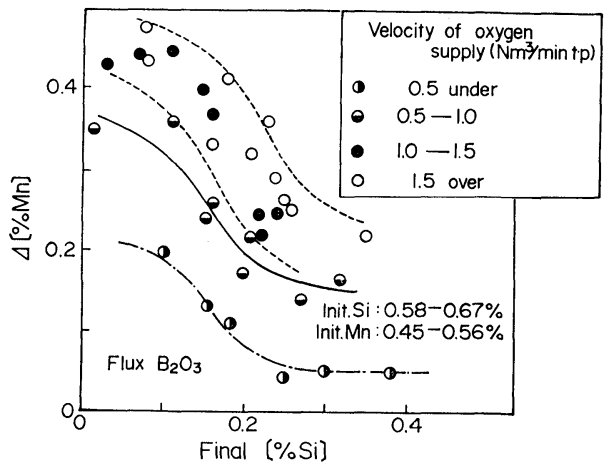

Fig. 3. Relation between final $[\% \mathrm{Si}]$ and $\Delta[\% \mathrm{Mn}]$ in desiliconization treatment.

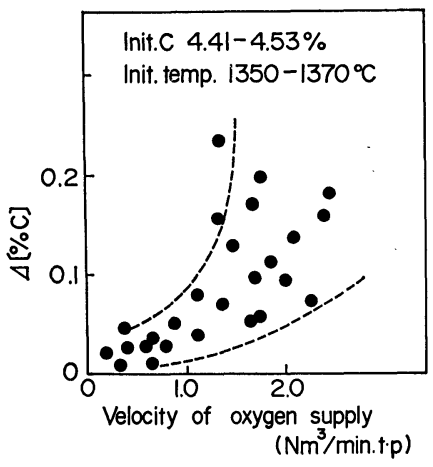

Fig. 4. Relation between velocity of oxygen supply and $\Delta[\% \mathrm{C}]$.

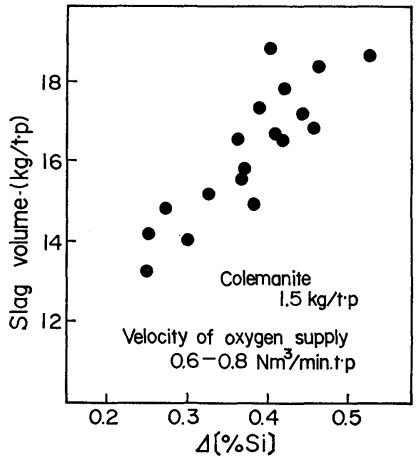

Fig. 5. Relation between slag volume and $4[\% \mathrm{Si}]$ by desiliconization treatment.

Table 3. Chemical composition of desiliconization and LD slags. (wt\%)

\begin{tabular}{r|c|rrrrrrrrr}
\hline & $\mathrm{CaO}$ & $\mathrm{SiO}_{2}$ & $\mathrm{~T} . \mathrm{Fe}$ & $\mathrm{MnO}$ & $\mathrm{MgO}$ & $\mathrm{TiO}_{2}$ & $\mathrm{~B}_{2} \mathrm{O}_{3}$ & $\mathrm{P}_{2} \mathrm{O}_{5}$ & $\mathrm{~S}$ \\
\hline \multirow{2}{*}{$\mathrm{SMP}$} & $\mathrm{De} \cdot \mathrm{Si}$ & 3.1 & 48.7 & 18.2 & 19.0 & 1.3 & 4.9 & 3.6 & 0.06 & 0.05 \\
& $\mathrm{LD}$ & 46.1 & 9.5 & 23.2 & 4.5 & 3.2 & 1.6 & 0.3 & 4.75 & 0.09 \\
\hline \multicolumn{2}{l}{ Conventional LD } & 40.3 & 17.2 & 17.9 & 6.9 & 5.6 & 1.0 & 0.8 & 2.04 & 0.07 \\
\hline
\end{tabular}


amount of desiliconization. For example, this volume is 17 to $19 \mathrm{~kg} / \mathrm{t}-\mathrm{p}$ when silicon is decreased from 0.60 to $0.15 \%$.

Since desiliconized slag contains as high as 40 to $55 \%$ of $\mathrm{SiO}_{2}$ and, further, such valuable components as iron and manganese, examination was made as to its recycling as the source of $\mathrm{SiO}_{2}$ in the sintering process. It was found as a result, that the whole quantity of desiliconized slag that does not contain phosphorus or sulphur can be recycled. Consequently, it is necessary to retard also dephosphorization and desulphurization the desiliconization treatment, and also in this respect, it is beneficial to use colemanite rather than $\mathrm{CaO}$ as the flux.

\section{LD Refining of Low-silicon Hot Metal}

\section{(1) Dephosphorization}

Figure 6 shows the relationship between the final phosphorus content and the final carbon content obtained by reducing the silicon in hot metal from 0.18 to $0.24 \%$ and then conducting dephosphorization and decarburization in $50 \mathrm{t}$ and $120 \mathrm{t} \mathrm{LD}$ converters. In the $\mathrm{LD}$ refining, $\mathrm{CaO}$ consumption suited to the silicon in hot metal was calculated from a dephosphorization equilibrium formula and a slag balance formula using the method shown below. As is apparent from Fig. 6, by reducing the silicon in hot metal to about $0.20 \%$, it is possible to save $\mathrm{CaO}$ consumption substantially and to obtain a final phosphorus content comparable to that obtained by the conventional LD steelmaking process.

Figure 7 shows the relationship between the initial silicon content of hot metal and the $\mathrm{CaO}$ consumption

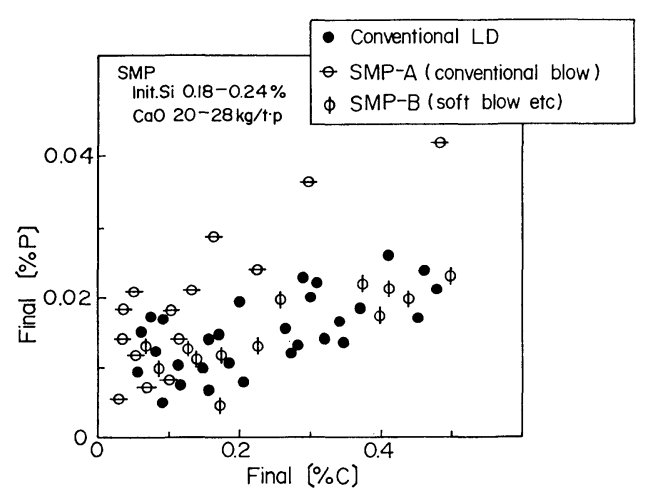

Fig. 6. Relation between final $[\% \mathrm{C}]$ and final $[\% \mathrm{P}]$ in $50 \mathrm{t}$ LD.

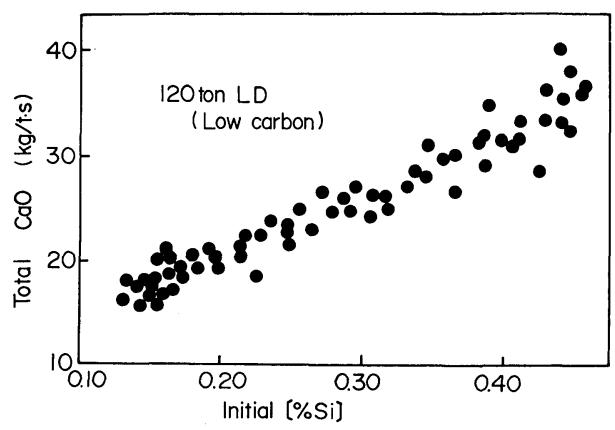

Fig. 7. Relation between $\mathrm{CaO}$ consumption and initial [\% $\mathrm{Si}]$ in $\mathrm{LD}$ refining. in the production of low-carbon rimmed steel (final $\mathrm{C}<0.1 \%$ ) using a $120 \mathrm{t} \mathrm{LD}$ converter. Conventionally, the silicon content of hot metal is 0.5 to $0.6 \%$ and $\mathrm{CaO}$ is supplied in quantities of 40 to 45 $\mathrm{kg} / \mathrm{t}$-s. However, $\mathrm{CaO}$ can be saved due to a decrease in the silicon content of hot metal. When the silicon in hot metal is $0.15 \%, \mathrm{CaO}$ consumption is 16 to $20 \mathrm{~kg} / \mathrm{t}$-s. This range is less than half the $\mathrm{CaO}$ consumption by the conventional LD steelmaking process. The slag composition in this case is shown in Table 3. It is obvious that the decrease in the dephosphorization capacity due to a reduced slag volume is compensated for by high basicity and high T.Fe.

The relationship between the silicon content of hot metal and the dephosphorization ratio is shown in Fig. 8. It is apparent from the figure that the dephosphorization ratio tends to be stable at high levels when hot metal with $\mathrm{Si}$ content less than $0.20 \%$ is refined. This is considered, as will be described later, due to the fact that even in refining with a small slag volume, slagging of $\mathrm{CaO}$ is promoted by soft blowing, $\mathrm{CaF}_{2}$ addition, etc., and that the fluctuation of slag formation decreases.

Figure 9 shows the dephosphorization equilibrium of the conventional LD steelmaking process and the SMP, obtained using the dephosphorization equilibrium formula ${ }^{3)}$ proposed by Yamamoto et al., based on the dephosphorization equilibrium formula of Balajiva et al.4) As is apparent from this figure, the dephosphorization equilibrium of SMP in the hot metal silicon range of 0.26 to $0.35 \%$ is almost on a

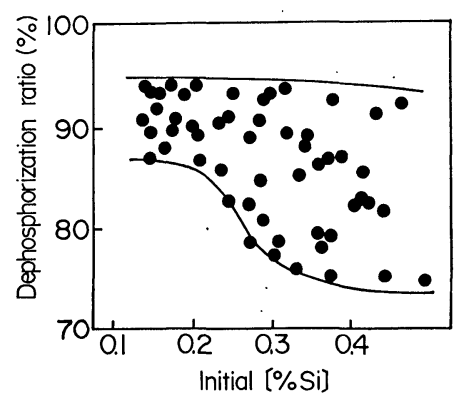

Fig. 8. Relation between dephosphorization ratio and initial $[\% \mathrm{Si}]$ in $\mathrm{LD}$ refining.

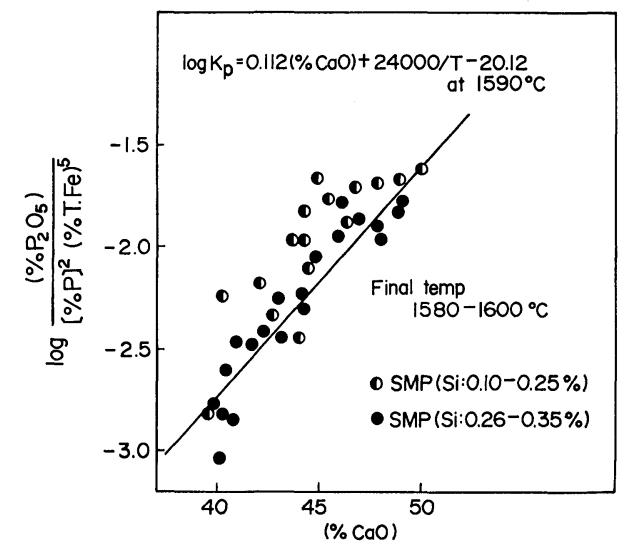

Fig. 9. Dephosphorization equilibrium by modified Balajiva's formula. 
level with that of the conventional LD steelmaking process, while it tends to shift a little toward the positive side when the silicon content of hot metal is $0.25 \%$ or less. This corresponds with an increase in the phosphorus distribution.

(2) Other Metallurgical Reactions in LD Converter

The relationship between the silicon content of hot metal and the demanganization ratio was arranged with respect to demanganization, and it became clear that the demanganization ratio has a tendency to decrease with decreasing silicon content of hot metal. As will be discussed later, this seems due to the fact that the slag volume participates in the demanganization equilibrium.

The desulphurization ratio in the SMP is somewhat low. This is considered to be caused by the effect of the decrease in the slag volume.

As for decarburization, no particular difference was observed between the SMP and conventional LD steelmaking process.

(3) Volume of Slag Formed and Erosion of Refractories

Figure 10 shows the relationship between $\mathrm{MgO}$ dissolution and the slag volume. In the SMP, as it already known, ${ }^{5)}$ the $\mathrm{MgO}$ dissolution from LD converter refractories is restricted by the decrease of slag volume accompanying the reduction of silicon content in hot metal. Hence, it is possible to reduce refractory costs.

When the volume of slag formed was measured, it was found substantially decreased to 40 to $45 \mathrm{~kg} / \mathrm{t}$-s (low-carbon rimmed steel) at $0.15 \%$ slag in hot metal. This is in good agreement with the slag volume estimated from the phosphorus balance. Further, as it is apparent from Table 3 , the $\mathrm{P}_{2} \mathrm{O}_{5}$ content of slag has increased to above $4 \%$, and an effective utilization of this component as fertilizer can be expected.

\section{Evaluation of SMP as Total Process}

Based on the results of the experiments, the SMP as a total process was evaluated in consideration of the hot metal conditions at the Muroran Works of Nippon Steel Corp.

Figure 11 shows the flow diagram of SMP together with $\mathrm{CaO}$ consumption, volume of slag formed, etc., for the refining of low-carbon rimmed steel in comparison with the conventional LD steel making process. As is evident from the diagram, desiliconization of hot metal enables the $\mathrm{CaO}$ consumption and volume of slag formed to be reducted by half. The silicon content of hot metal after desiliconization treatment was set around $0.15 \%$, which corresponds to about $0.25 \%$ in the limit manganese content of initial hot metal, necessary for securing the predetermined manganese content at the end point of LD refining.

Figures 12 and 13 show the iron balance and heat balance of the SMP and conventional LD steelmaking process, respectively, for the refining of low-carbon rimmed steel. In the case of SMP, the decrease in the iron loss and heat loss associated with the reduced

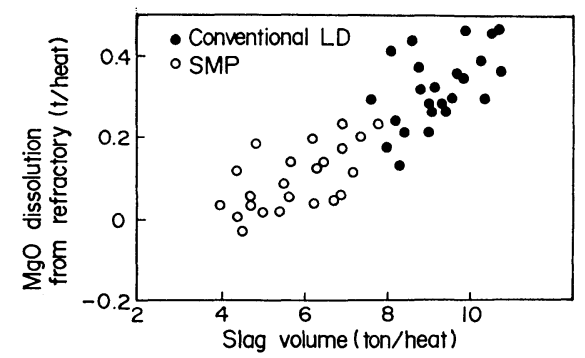

Fig. 10. Relation between slag volume and $\mathrm{MgO}$ dissolution from refractory.

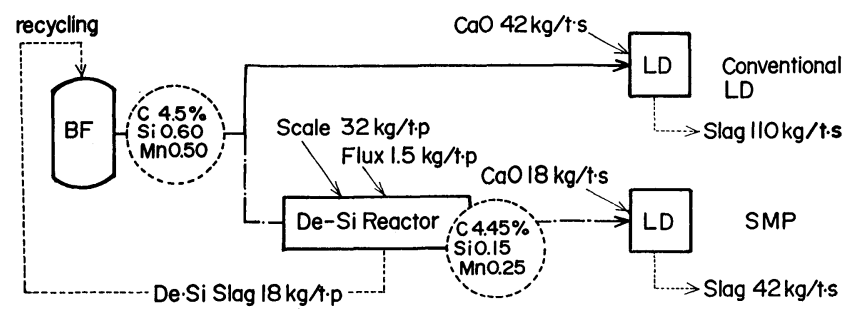

Fig. 11. Total flow of SMP. (Refining of low carbon rimmed steel)

volume of slag formed in LD refining is more than enough to compensate for the iron loss and heat loss caused by the incorporation of the desiliconization process. As a result, the iron yield in the total process increases, and further, a greater volume of scrap can be used in LD refining without posing no particular problem related to heat restriction.

Table 4 shows a comparison of overall effects between the SMP and conventional process. As it is apparent from the table, the SMP permits a substantial cost reduction in the steelmaking process, due to the reduction of sub-material costs, improved iron yield, and the elimination of the necessity for measures to treat the slag formed.

\section{Construction and Operation of SMP Plant}

A full-scale plant for the desiliconization treatment of hot metal was constructed based on the results of the experiments mentioned above. This plant was brought into commercial operation in October, 1979, and has since been operating smoothly.

The desiliconization system is simple: solid iron oxide is supplied through a charging chute during the agitation of hot metal in a torpedo car or hot metal ladle by top-blown $\mathrm{N}_{2}$ gas. The exhaust gas equipment is very small scale because of the establishment of the preferential desiliconization technique. For de-slagging before and after the desiliconization treatment, a compact mechanical device made up of a modified forklift is used.

Part of the desiliconization equipment began operation on July 17, 1979, and a test run was stared. With the completion of the entire equipment on October 18, 1979, the SMP plant was brought into full-scale operation. The amount of hot metal treated by this plant increased smoothly and, in the first half of 1979, almost all the hot metal for steelmaking was treated by this plant. The silicon content was stably 


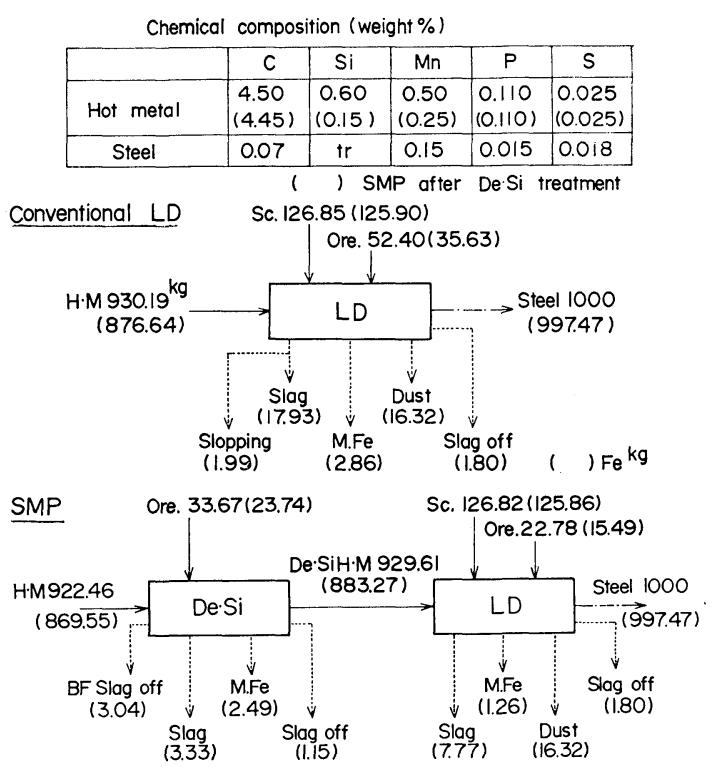

Sc.: Scrap

Fig. 12. Fe balance at conventional LD and SMP.

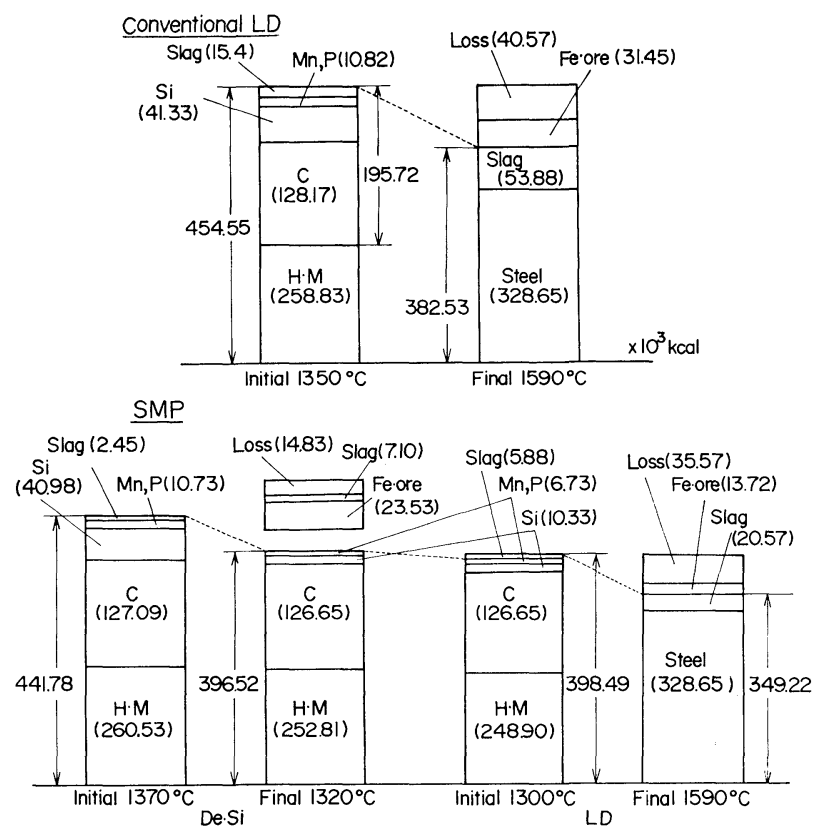

Fig. 13. Heat balance at conventional LD and SMP.

decreased from 0.60 to $0.15 \%$ by supplying mill scale in quantities of 30 to $35 \mathrm{~kg} / \mathrm{t}$-p. Also LD refining was carried out smoothly, as shown in Fig. 14, and substantial cost reduction, as expected from the development experiments, was achieved.

\section{Considerations}

\section{Hot Metal Desiliconization by Solid Iron Oxide}

1. Effect of Velocity of Oxygen Supply on Preferential Desiliconization

As described above, it is desirable in the hot metal desiliconization process, to retard the oxidation of carbon and manganese as far as possible and oxidize and remove only silicon preferentially. Therefore, examination was made as to the effect of the velocity
Table 4. Economical effects of SMP. (Refining of low carbon rimmed steel).

\begin{tabular}{|c|c|c|}
\hline & SMP & $\begin{array}{l}\text { Conven- } \\
\text { tional LD }\end{array}$ \\
\hline $\begin{array}{l}\text { Quantity of } \mathrm{CaO} \\
(\mathrm{kg} / \mathrm{t}-\mathrm{s})\end{array}$ & 18 & 42 \\
\hline Iron yield & $\begin{array}{l}\text { Reduced amount of slag, } \\
\text { reduced slopping, etc., } \\
\text { improve the iron yield } \\
\text { by } 0.5 \text { to } 0.7 \text { \% over the } \\
\text { conventional LD }\end{array}$ & \\
\hline Refractory cost & 0.3 to 0.5 & 1 \\
\hline $\begin{array}{l}\text { Utilization of } \\
\text { steelmaking slag }\end{array}$ & $\begin{array}{l}\text { Utilization of de-Si slag } \\
\text { for sintering process }\end{array}$ & \\
\hline $\begin{array}{l}\text { Controllability } \\
\text { at } \mathrm{LD} \text { refining }\end{array}$ & $\begin{array}{l}\text { More controllable by } \\
\text { stability of hot metal } \\
\text { components and non- } \\
\text { slopping }\end{array}$ & \\
\hline
\end{tabular}

120-t LD

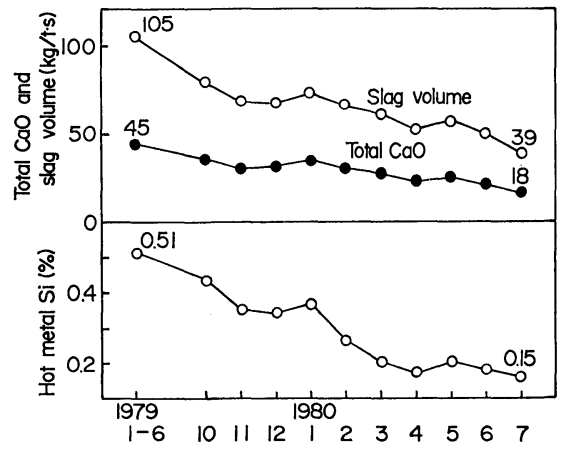

Fig. 14. Transition of $\mathrm{LD}$ refining. (300 $\mathrm{t} \mathrm{LD})$

of oxygen supply as one of the preferential desiliconization conditions.

The apparent velocity of oxygen supply based on the gaseous oxygen conversion, $V_{\mathrm{O}_{2}}$ was defined by Eq. (1) and the relationship between $V_{\mathrm{O}_{2}}$ and the ratio of the oxygen combined with silicon to the total oxygen supplied, $\alpha_{\mathrm{Si}}$, was determined.

$$
V_{\mathrm{O}_{2}}=(22.4 / 32) \alpha W / \theta
$$

where, $\alpha$ : Oxygen content of formed iron oxide in desiliconizing agent

$W$ : Volume of desiliconizing agent supplied (kg/t-p)

$\theta$ : Time of desiliconizing agent supply (min)

$V_{\mathrm{O}_{2}}$ : Apparent velocity of oxygen supply based on gaseous oxygen conversion $\left(\mathrm{Nm}^{3} / \mathrm{min} \cdot \mathrm{t}-\mathrm{p}\right)$.

As shown in Fig. 15, the lower $V_{\mathrm{O}_{2}}$, the higher $\alpha_{\text {Si }}$. Further, as is evident from the experiment result, decarburization and demanganization are retarted in this case, and hence preferential desiliconization is possible.

Because oxygen supply becomes insufficient by lowering $V_{\mathrm{O}_{2}}$, unlike that at the initial stage of LD refining, and the hot metal temperature is as low as 1300 to $1400^{\circ} \mathrm{C}$, only silicon is considered to be preferentially oxidized due to a difference in free energy 
of oxidizing reaction of each element.

\section{Effect of Iron Oxide Composition on Preferential} Desiliconization

A difference between mill scale and sinter similar to that shown in Fig. 2 is also evident in terms of the relation between $V_{\mathrm{O}_{2}}$ and $\alpha_{\mathrm{Si}}$. This difference in the reactivity of desiliconizing agent is considered mainly due to the difference in the composition of iron oxide. If the reaction of iron oxide to the silicon, carbon and manganese in hot metal is considered a melting one, $\left.{ }^{6}\right)$ the reducting reaction $\mathrm{FeO} \rightarrow \mathrm{Fe}$ occurs with mill scale, where as the reducting reaction $\mathrm{Fe}_{2} \mathrm{O}_{3} \rightarrow \mathrm{Fe}_{3} \mathrm{O}_{4}$ $\rightarrow \mathrm{FeO} \rightarrow \mathrm{Fe}$ takes place with sinter. In this case, from a study on the reaction of iron oxides by $\mathrm{CO}$ gas, ${ }^{7)}$ the reducting velocity is considered to be expressed by $\mathrm{Fe}_{2} \mathrm{O}_{3} \rightarrow \mathrm{Fe}_{3} \mathrm{O}_{4}>\mathrm{Fe}_{3} \mathrm{O}_{4} \rightarrow \mathrm{FeO}>\mathrm{FeO} \rightarrow \mathrm{Fe}$. Therefore, when sinter is used, the actual velocity of oxygen supply is high even if $V_{\mathrm{O}_{2}}$ is the same as when mill scale is used. Since not only silicon but also carbon and manganese are oxidized, $\alpha_{\mathrm{Si}}$ is considered to become low.

3. Relationship between Preferential Desiliconization and Agitation Energy

The gas bubbling method by an immersion lance was adopted in the full-scale plant for preferential desiliconization. This is a simple agitation method. The agitation energy by this method was analyzed by Nakanishi et al. ${ }^{8)}$ The results shown in Fig. 16 were obtained when the agitation energy, $\dot{e}$, was determined with respect to the use of hot metal ladles and torpedo cars. In the figure, measurements of $\dot{e}$ for the KR agitation energy of the gas bubbling method is smaller than that of the KR method and is about half the latter when torpedo cars are used.

From this result, it is clear that to secure high $\alpha_{\mathrm{Si}}$

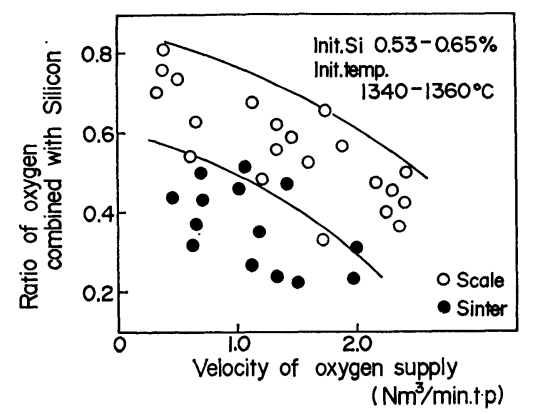

Fig. 15. Relation between velocity of oxygen supply and ratio of oxygen combined with silicon.

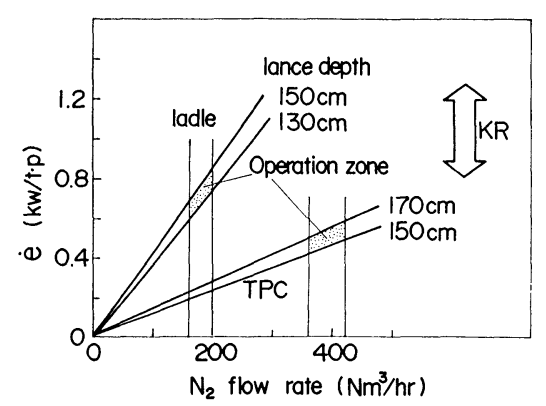

Fig. 16. Agitation energy by $\mathrm{N}_{2}$ top bubbling treatment. in the gas bubbling method, it is necessary to cope with the worsening of the contact and mixing of the desiliconizing agent with hot metal associated with a decrease in agitation energy. For this purpose, it is possible to contrive a method by which the velocity of oxygen supply is further decreased.

Desiliconization treatment was carried out based on the above mentioned concept. As shown in Fig. $17, \alpha_{\mathrm{Si}}$, comparable with that of the KR method, was obtained also in the gas bubbling method by lowering $V_{\mathrm{O}_{2}}$. This finding seems to be applicable to various agitation methods.

\section{Desiliconization Rate}

The behaviour of desiliconization was described earlier. Some consideration was given to this behaviour by definding the zone where silicon decreases linearly as L-Zone and the zone where silicon decreases exponentially as E-Zone.

Factors that affect the average desiliconization rate, $V_{\mathrm{Si}}$, in L-Zone were analyzed and it was found that as shown in Fig. 18, the relation with $V_{\mathrm{O}_{2}}$ is the strongest. As analyzed by Fukuzawa, ${ }^{9}$ the desiliconizing reaction in the conventional LD steelmaking process can be practically arranged as a first order reaction, while the rate-determining step of the desiliconizing reaction is regarded as the oxygen supply process when oxygen supply is very slow as in this experiment. However, the value of $\Delta V_{\mathrm{Si}} / \Delta V_{\mathrm{O}_{2}}$ decreases with increasing $V_{\mathrm{O}_{2}}$, resulting in $V_{\mathrm{Si}} \propto\left(V_{\mathrm{O}_{2}}\right)^{2 / 3}$.

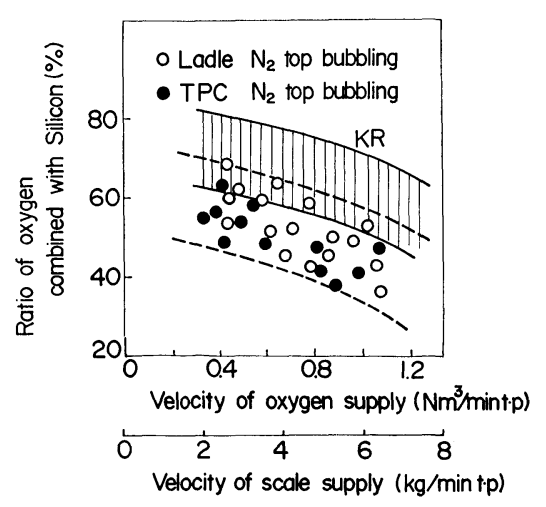

Fig. 17. Relation between velocity of oxygen supply and ratio of oxygen combined with silicon by $\mathrm{N}_{2}$ top bubbling treatment.

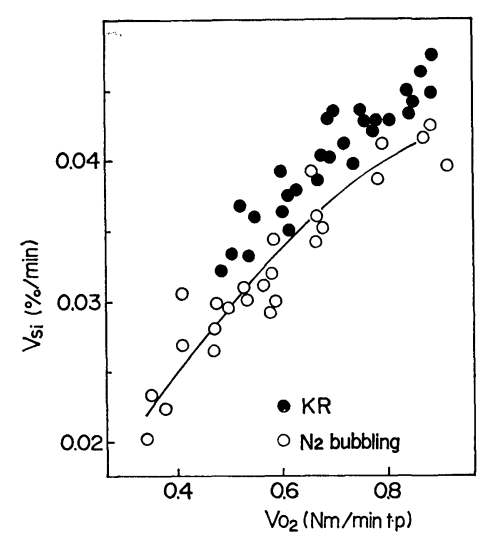

Fig. 18. Relation between $V_{\mathrm{O}_{2}}$ and $V_{\mathrm{Si}}$. 
This agrees with the tendency that $\alpha_{\mathrm{Si}}$ decreases with increasing $V_{\mathrm{O}_{2}}$. From Fig. 18, the effect of agitation energy on $V_{\mathrm{Si}}$ is also apparent. It seems that this is because the higher the agitation energy, the larger the area of contact between hot metal and the solid iron oxide supplied, thereby increasing the velocity of oxygen supply.

In E-Zone, the speed of travel of silicon to the reaction interface is considered to decrease due to the decrease in silicon content. Such measures as intensifying the agitation energy and reducing $V_{\mathrm{O}_{2}}$ will be effective in causing silicon to be oxidized preferentially.

\section{LD Refining of Low-silicon Hot Metal}

1. Relationship between Si Content in Hot Metal and the Required CaO Consumption and Slag Volume

From the results of LD refining of low-silicon hot metal, it was ascertained that the required $\mathrm{CaO}$ consumption and slag volume decrease due to the decrease in the silicon content of hot metal. This relationship was considered by a new method using a dephosphorization equilibrium formula and a slag balance formula.

The dephosphorization equilibrium formula (2) is rewritten by Eq. (3) if the amount of $\mathrm{CaO}$ added is denoted by $W_{\mathrm{CaO}}$, the slag volume by $W_{s}$ and the amount of dephosphorization by $\Delta[\% \mathrm{P}]$ and assuming that the $\mathrm{CaO}$ added is $100 \%$ slagged. (The dephosphorization equilibrium formula for the conventional LD steelmaking process was adopted as the basis for the SMP)

$$
\begin{aligned}
& \log \frac{\left(\% \mathrm{P}_{2} \mathrm{O}_{5}\right)}{[\% \mathrm{P}]^{2}(\% \mathrm{~T} . \mathrm{Fe})^{5}}=0.112(\% \mathrm{CaO})+\frac{24000}{\mathrm{~T}} \\
& -20.12 \\
& \log \frac{22.9\left(\Delta[\% \mathrm{P}] / W_{s}\right) \times 10^{2}}{[\% \mathrm{P}]^{2}(\% \mathrm{~T} . \mathrm{Fe})^{5}}=11.2\left(W_{\mathrm{CaO} /} / W_{s}\right) \\
& +\frac{24000}{T}-20.12
\end{aligned}
$$

Since the slag volume, $W_{s}$, is the sum of each component of slag,

$$
\begin{aligned}
W_{s}= & W_{\mathrm{CaO}}+21.4 \Delta[\% \mathrm{Si}]+12.9 \Delta[\% \mathrm{Mn}] \\
& +22.9 \Delta[\% \mathrm{P}]+(a+b) W_{s} \ldots \ldots \ldots \ldots \ldots
\end{aligned}
$$

where $\Delta[\% \mathrm{Si}]$ and $\Delta[\% \mathrm{Mn}]$ are the amount of desiliconization and the amount of demanganization, respectively, and $a$ and $b$ denote the $\mathrm{FeO}$ and $\mathrm{MgO}$ contents of slag, respectively.

If in Eqs. (3) and (4), $\Delta[\% \mathrm{Mn}], T, a$ and $b$ are given, it is possible to obtain the required $\mathrm{CaO}$ consumption and slag volume for obtaining a definite amount of dephosphorization using $\Delta[\% \mathrm{Si}]$, i.e., silicon in hot metal as a parameter.

The relationship between the initial silicon content of hot metal and the required $\mathrm{CaO}$ consumption, slag volume, etc., was determined for a low-carbon rimmed steel with a final carbon content of $0.1 \%$ or less. The result is shown in Fig. 19. As is apparent from the figure, assuming that $\mathrm{CaO}$ is $100 \%$ slagged, it is possible to reduce the $\mathrm{CaO}$ consumption and slag volume with a decrease in the silicon content of hot metal. For example, when the silicon content is $0.20 \%$, the required $\mathrm{CaO}$ consumption is $18 \mathrm{~kg} / \mathrm{t}-\mathrm{p}$ and the slag volume is about $35 \mathrm{~kg} / \mathrm{t}-\mathrm{p}$. Conversely, however, the slag basicity increases. This suggests that it is necessary to make up for the decrease in slag volume by a high basicity composition.

\section{Slag Formation Ratio of $\mathrm{CaO}$ and Features of SMP}

The non-slagging of $\mathrm{CaO}$ is expected in actual refining. Therefore, to make clear the relationship between $\mathrm{CaO}$ slagging and refining conditions, calculated curves for the refining of hot metal with a silicon content, were determined with respect to the relationship of the amount of $\mathrm{CaO}$ added and the final phosphorus content determined from Eqs. (3) and (4), using the slag formation ratio (SFR) of $\mathrm{CaO}$ as a parameter. Actual values for the respective refining conditions were plotted against these curves, as shown in Fig. 20. Since a low-carbon rimmed steel was produced as shown in the figure, the final phosphorus content obtained was on a level with that obtained by the existing LD plant even when the same blowing pattern as that of the conventional LD steelmaking process was employed. The SFR was 70 to $80 \%$ in this case. However, the SFR increases to 80 to $90 \%$ by carrying out some soft blowing at the final stage of refining, or it increases to above $90 \%$ by the addition of a small amount of $\mathrm{CaF}_{2}$ (about $0.5 \mathrm{~kg} / \mathrm{t}-\mathrm{s}$ ). The SFR of the conventional LD steelmaking process was determined for comparison, it ranged from 65 to $85 \%$. Thus, in the refining of hot metal with a silicon content of $0.25 \%$ or less, $\mathrm{CaO}$ slagging is easily promoted through soft blowing or the addition of a small amount of $\mathrm{CaF}_{2}$, and, at the same time, the fluctuation of the slag formation ratio decreases, permitting effective dephosphorization. This is the largest feature of the SMP. Furthermore, in the refining of hot metal of $0.25 \%$ or less silicon content, the slopping phenomenon does not take place at all due to the substantial decrease in slag volume, therefore, stable LD converter operation is expected, as is more effective refining.

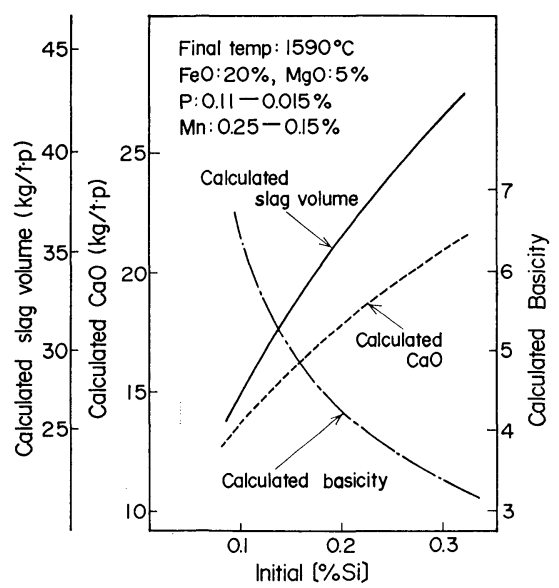

Fig. 19. Relation between initial $[\% \mathrm{Si}]$ and calculated $\mathrm{CaO}$, slag volume, basicity by modified Balajiva's formula. 


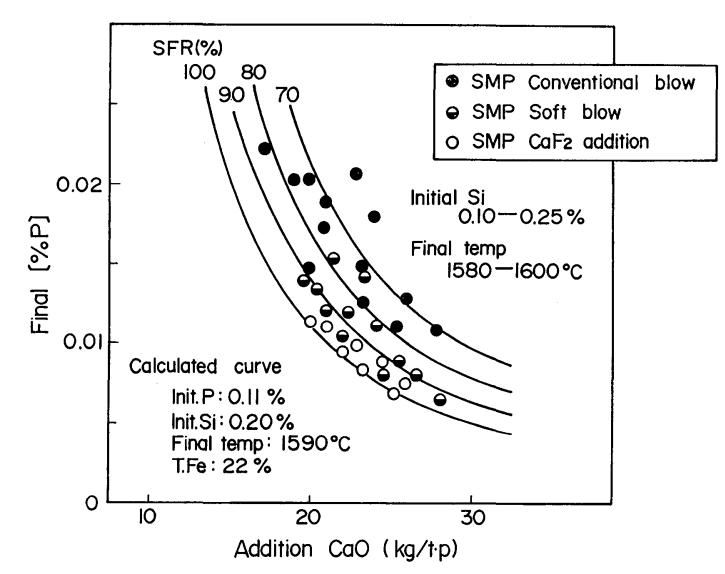

Fig. 20. Relation between addition $\mathrm{CaO}$ and final $[\% \mathrm{P}]$.

\section{Demanganizing Reaction in SMP}

In the SMP, the final manganese content is almost on a level with that obtained by the conventional LD steelmaking process in spite of the lower initial manganese content. Some assumptions were made in this respect and analysis was made.

If the demanganizing reaction is considered to proceed according to the following formula,

$$
\mathrm{Mn}+(\mathrm{FeO}) \rightleftarrows(\mathrm{MnO})+\mathrm{Fe}
$$

then the demanganization equilibrium formula is given by Eq. (6) by Gero et al. ${ }^{10)}$

$$
\log \left(a_{\mathrm{MnO}} / a_{\mathrm{Mn}} a_{\mathrm{FeO}}\right)=(6440 / \mathcal{T})-2.95
$$

where $a_{\mathrm{MnO}}, a_{\mathrm{FeO}}$, and $a_{\mathrm{Mn}}$ are the activity of $\mathrm{MnO}$, $\mathrm{FeO}$ and $\mathrm{Mn}$, respectively. Each activity is assumed: $a_{\mathrm{Mno}} \simeq r_{\mathrm{Mno}}(\% \mathrm{MnO}), \quad a_{\mathrm{FeO}} \simeq r_{\mathrm{FeO}}(\% \mathrm{FeO})$ and $a_{\mathrm{Mn}} \simeq$ $[\% \mathrm{Mn}]$, and the ratio of activity coefficients of $\mathrm{MnO}$ and $\mathrm{FeO}, r=r_{\mathrm{MnO}} / r_{\mathrm{FeO}}$, is defined.

$$
\log \frac{r(\% \mathrm{MnO})}{[\% \mathrm{Mn}](\% \mathrm{FeO})}=\frac{6440}{T}-2.95
$$

where, $(\% \mathrm{MnO}):$ weight percent of $\mathrm{MnO}$ in slag $(\% \mathrm{FeO}):$ weight percent of $\mathrm{FeO}$ in slag $\% \mathrm{Mn}$ : weight percent of $\mathrm{Mn}$ in metal.

If the slag volume is denoted by $W_{s}$, the initial manganese content by $\left[\% \mathrm{Mn}^{0}\right]$ and the final manganese content by $\left[\% \mathrm{Mn}^{f}\right]$, then $(\% \mathrm{MnO})=1290$. $\left\{\left[\% \mathrm{Mn}^{0}\right]-\left[\% \mathrm{Mn}^{f}\right]\right\} / W_{s}$, and finally Eq. (8) is obtained as the demanganization equilibrium formula

$$
\begin{aligned}
\frac{\left[\% \mathrm{Mn}^{0}\right]}{\left[\% \mathrm{Mn}^{f}\right]}= & \frac{W_{s}(\% \mathrm{FeO})}{1290 r} \exp \left\{2.3\left[\frac{6440}{T}-2.95\right]\right\} \\
& +1 \ldots \ldots \ldots \ldots \ldots \ldots \ldots \ldots \ldots \ldots \ldots \ldots \ldots \ldots \ldots \ldots \ldots \ldots \ldots \ldots \ldots \ldots \ldots \ldots \ldots \ldots \ldots \ldots
\end{aligned}
$$

Then the effects of $\left[\% \mathrm{Mn}^{0}\right], W_{s}$ and $r$ on the final manganese content were determined using Eq. (8). By setting the $W_{s}$ for the conventional LD steelmaking process equal to $100 \mathrm{~kg} / \mathrm{t}-\mathrm{p}$ and the $W_{s}$ for the SMP equal to $50 \mathrm{~kg} / \mathrm{t}-\mathrm{p}$, the relationship between $\left[\% \mathrm{Mn}^{0}\right]$ and $\left[\% \mathrm{Mn}^{f}\right]$ was determined for each $r$-value, and actual values were plotted as shown in Fig. 21. Also from $\mathrm{Eq}$. (8), it is estimated that the final manganese content is independent from the initial manganese content. As shown in Fig. 21, in the $\mathrm{SMP}, W_{s}$ is

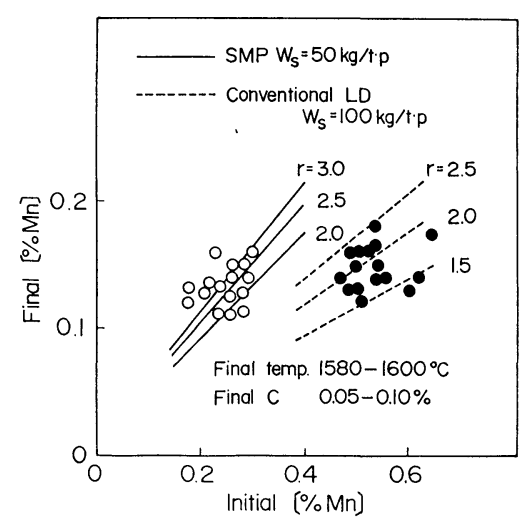

Fig. 21. Effect of slag volume and $r$ on manganese slagmetal distribution.

small and $r$ is large due to a high basicity composition. ${ }^{11)}$ Therefore, the final manganese content in the SMP is on a level with that of the LD steelmaking process. This is considered to result in the decrease in manganese loss. This point is also one of the features of the SMP.

\section{Conclusion}

The conventional LD steelmaking process was reexamined in order to improve the refining efficiency. As a result, it was concluded that a reduction of the slag volume is of importance for making the steelmaking process more efficient, and a new process, the slag minimum refining process (SMP), was conceived. This new process consists of hot metal desiliconization in hot metal containers and dephosphorization and decarburization in LD converters. Development experiments were carried out using existing facilities and the metallurgical advantages of hot metal desiliconization was ascertained. Based on the experiment results, this new steelmaking process was successfully commercialized.

(1) In the desiliconization treatment of hot metal, solid iron oxide such as mill scale is added as the desiliconizing agent during the agitation of hot metal. By properly controlling the rate of desiliconizing agent supply, the amount of decarburization and the amount of demanganization are held below 0.10 and $0.25 \%$, respectively, and the silicon in hot metal can be preferentially oxidized and reduced from the initial content of $0.60 \%$ to the final content of $0.15 \%$. The desiliconization treatment of hot metal can be performed in hot metal ladles or torpedo cars an immersion lance and installing a small-scale dust collector. Further, the process poses no matching problem with conventional LD converter operation.

(2) In LD refining, it is possible to substantially reduce the $\mathrm{CaO}$ consumption and slag volume for dephosphorization due to the decrease in the silicon content of hot metal by the desiliconization treatment. For example, when the initial silicon content is $0.60 \%$, the conventional LD steelmaking process requires up to $40 \mathrm{~kg} \mathrm{CaO}$ per tonne of steel and up to $110 \mathrm{~kg}$ slag per tonne of steel, whereas in the SMP, the $\mathrm{CaO}$ consumption and slag volume can be re- 
duced to $18 \mathrm{~kg} / \mathrm{t}$-s and $42 \mathrm{~kg} / \mathrm{t}$-s, respectively, by lowering the initial silicon content to $0.15 \%$. Further, at initial silicon contents of $0.25 \%$ or less, it is easy to control slag properties and slopping does not occur, permitting efficient dephosphorizing refining. Furthermore, the reduction of iron and heat losses, extention of refractory life and other effects due to the decrease in slag volume were ascertained. Thus, the prospect for a substantial cost reduction in the steelmaking process was obtained.

(3) The SMP produces desiliconized slag and LD slag. It is possible to recycle the whole quantity of desiliconized slag to the sintering process as the source of $\mathrm{SiO}_{2}$.

\section{REFERENCES}

1) Y. Itoh, T. Okajima, Y. Kawauchi and A. Koshida: Tetsu-to-Hagané, 62 (1976), S77.
2) Y. Itoh, T. Okajima, Y. Kawauchi, T. Kuwabara, T. Iwata and T. Takahashi: Tetsu-to-Hagané, 62 (1976), S78.

3) M. Yamamoto, H. Yoshii and S. Murakami: Seitetsu Kenkyu, 264 (1968), 21.

4) K. Balajiva, A. G. Quarrell and P. Vajragupta: JISI, 154 (1946), 115.

5) Y. Doi: Tenro-seikoho, Nikkan Kogyo Shinbun-sha, Tokyo, (1966), 81.

6) K. Sasaki, S. Fukagawa and T. Sohma: Tetsu-to-Hagané, 61 (1974), S11.

7) Y. Kodama, A. Shigemi and T. Azuma: Tetsu-to-Hagané, 46 (1960), 1138.

8) K. Nakanishi, T. Fuju and J. Szekely: Trans. ISIJ, 2 (1975), 193.

9) A. Fukuzawa: Tetsu-to-Hagané, 59 (1973), S412.

10) J. B. Gero, T. B. Winkler and J. Chipman: Trans. AIME, 188 (1950), 341.

11) D. G. Hilty, R. W. Farley and D. J. Girardi: Electric Furnace Steelmaking, II, (1963), 206. 